\title{
LA ACTIVIDAD DESARROLLADA POR LAS CORTES EN LA SITUACIÓN DE LEGISLATURA FALLIDA Y DE GOBIERNO EN FUNCIONES
}

\section{The Activity Developed by the Parliament in the Situation of Failed Legislative Term and of Caretaker Government}

\author{
ISABEL M. GIMÉNEZ SÁNCHEZ \\ Universidad Autónoma de Madrid \\ isabel.gimenez@uam.es
}

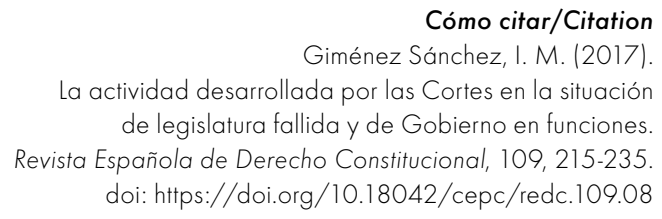

Resumen

En este artículo se analizan los principales problemas jurídico-constitucionales suscitados en relación con la actividad parlamentaria desempeñada durante los trescientos dieciséis días de Gobierno en funciones, que han abarcado dos legislaturas distintas y han supuesto una gran variedad de situaciones nunca antes vividas en nuestra democracia. Se estudia especialmente la extensión de la facultad de control y de iniciativa legislativa de que dispone el Parlamento en este período de interinidad del Ejecutivo. Asimismo, trataremos especialmente la cuestión del alcance de la facultad del Gobierno de otorgar su conformidad a las iniciativas legislativas parlamentarias por aumento de crédito o disminución de ingresos.

\section{Palabras clave}

Derecho parlamentario; Gobierno en funciones; función de control; iniciativa legislativa; investidura; conformidad el Gobierno; conflicto de atribuciones entre órganos del Estado. 


\begin{abstract}
This article analyzes the main constitutional issues raised around the parliamentary activity performed during the 316 days of incumbent government. This period of interim had spanned two different legislatures and had meant a great variety of situations never before experienced in our democracy. Special consideration is given to the extension of the accountability and legislative initiative available to our Parliament in this Executive's interim period. We will also deal in particular with the question of the scope of the Government's power to accord to parliamentary legislative initiatives when increasing credit or decreasing revenues.
\end{abstract}

\title{
Keywords
}

Parliamentary law; Incumbent Government; Caretaker Government; accountability; ability to initiate legislation; investiture of the prime minister; conflict of powers between State institutions. 
I. INTRODUCCIÓN. II. INVESTIDURA DEL PRESIDENTE DE GOBIERNO. III. FUNCIÓN DE CONTROL AL GOBIERNO. IV. FUNCIÓN LEGISLATIVA DEL PARLAMENTO CON UN GOBIERNO EN FUNCIONES. V. EL VETO PRESUPUESTARIO DEL GOBIERNO. VI. OTRAS INICIATIVAS. BIBLIOGRAFIA.

\section{INTRODUCCIÓN}

El objeto de estudio de esta nota vendrá circunscrito al extraordinariamente prolongado período de Gobierno en funciones (trescientos dieciséis días) que ha abarcado más de cuatro meses de toda una legislatura fallida (la XI) y casi tres meses de arranque de la legislatura presente (la XII). En este tiempo se han sucedido toda una serie de situaciones hasta ahora inéditas en nuestra reciente historia constitucional.

Para ello analizaremos esta original situación vivida desde la perspectiva del Parlamento, al que, entre unos y otros, parecen haber pretendido convertir en un Parlamento en funciones ${ }^{1}$, con unas competencias muy mermadas, ya que, de un lado, se ha intentado privarlo de cualquier facultad de control al Gobierno en funciones; de otro, por cuanto respecta a la función legislativa, en la práctica desde el Gobierno en funciones se ha venido limitando su ejercicio al hacer uso reiterado de su prerrogativa de veto de aquellas proposiciones y/o enmiendas que supongan alteraciones presupuestarias. Además, veremos, una parte de la doctrina especializada en la materia sostiene que, en estos supuestos de Gobierno en funciones, tampoco cabe entender atribuida la iniciativa legislativa de las Cámaras. Llevándolo al extremo, podría llegar a decirse que la única atribución que de manera incontestada correspondería al Parlamento en estas situaciones de Gobierno en funciones sería la de investir al Gobierno.

Esto último, sin embargo, no es lo que ha ocurrido en la práctica, de modo que durante estos pasados meses se fueron presentando diversas proposiciones de ley (incluso de reforma de la Constitución española (CE) y de estatutos de autonomía). Analizaremos, pues, en las breves páginas que siguen, las distintas iniciativas presentadas y participadas por el Parlamento durante este peculiar interregno de trescientos dieciséis días ${ }^{2}$. Para ello,

García-Escudero Márquez (2016).

2 La Mesa de la Diputación Permanente, en su reunión del día 10 de mayo de 2016, acordó, una vez producida la disolución de la Cámara, publicar —ex art. 97 del 
además, seguiremos el informe emitido por la Secretaría General del Congreso de los Diputados sobre la actividad de la Cámara durante el período en que el Gobierno cesante se encuentra en funciones, con fecha de 19 de enero de $2016^{3}$.

\section{INVESTIDURA DEL PRESIDENTE DEL GOBIERNO}

Este aspecto en concreto ha supuesto una auténtica novedad en nuestra historia constitucional reciente, provocada por la ausencia de unos resultados que arrojasen un vencedor claro como hasta ahora había venido ocurriendo en las diez legislaturas previas. Dicho punto de partida acabó originando toda una sucesión de situaciones nunca antes vistas, con la consiguiente sensación de incertidumbre y expectativa generalizadas.

Para contextualizar la situación, permítaseme un breve resumen de los hechos. Comenzando con la situación resultante de las elecciones de 20 de diciembre de 2015, en vista de la fragmentación de las fuerzas políticas con representación parlamentaria, y de la falta de apoyos suficientes ${ }^{4}$, el líder de la

Reglamento del Congreso - tres listados referentes a distintos tipos de iniciativas parlamentarias en función de su momento de tramitación:

a) Relación de iniciativas ya calificadas que se hallaban en tramitación en el momento de la disolución y que han caducado como consecuencia de esta.

b) Relación de iniciativas pendientes de calificación caducadas como consecuencia de la disolución.

c) Relación de iniciativas que se trasladan a la Cámara que se constituya en la XII Legislatura.

3 Disponible en: http://www.eldiario.es/politica/servicios-Congreso-confirman-proyectos-Gobierno_0_477702399.html

4 El vencedor de las elecciones fue el Partido Popular, que obtuvo en el Congreso de los Diputados una mayoría simple de 123 escaños. El resto de las fuerzas políticas que obtuvieron representación parlamentaria fueron, por este orden: Partido Socialista Obrero Español, 90 diputados; Podemos, 42, a las que había que sumar los correspondientes a las coaliciones electorales autonómicas En Comú Podem (doce), Compromís-Podemos-És el moment (nueve) y En Marea (seis), obteniendo un resultado conjunto de 69 diputados; Ciudadanos-Partido de la Ciudadanía, 40 diputados; Esquerra Republicana de Catalunya-Catalunya Sí, nueve; Democràcia i Llibertat, ocho; Partido Nacionalista Vasco, seis; Unidad Popular: Izquierda Unida, Unidad Popular en Común, dos; Euskal Herria Bildu, dos; y Coalición Canaria-Partido Nacionalista Canario, uno. Puede comprobarse el detalle de estos resultados en el BOE del 29 de enero de 2016, donde se publica la Resolución de 26 de enero de 
lista más votada (Partido Popular [PP]) declinó ser candidato tras la oferta del rey (en palabras del comunicado hecho público por la Casa de su Majestad el Rey) $)^{5}$ o, dicho de otro modo, rechazó presentarse a la votación de investidura, una situación absolutamente inédita e inesperada que, entre otras cosas, impedía que empezara a transcurrir el plazo de los dos meses establecido en el art. 99 de la CE. Al margen de las discusiones acerca de si es posible o no rechazar la oferta del rey —una cuestión que de la que no trataremos aquí, dado que es abordada en detalle en otros artículos del presente volumen y que, al no haber propuesta formal del monarca no llegó a implicar la intervención del Parlamento-, ello forzó que, de nuevo por vez primera en nuestra historia constitucional, tuviera lugar una segunda ronda de consultas, tras la cual el rey propuso como candidato al líder de la segunda lista más votada (Partido Socialista Obrero Español [PSOE]), quien, pese a no contar a priori con los suficientes apoyos parlamentarios, aceptó ser candidato a la Presidencia de Gobierno en la votación de investidura ante el Parlamento (en rigor, eso fue lo que aceptó según se deriva del art. 99 de la CE y no, como llegó a afirmar el político aludido, «el encargo de intentar formar Gobierno $\left.»^{6}\right)$.

2016, de la Presidencia de la Junta Electoral Central, por la que se publica el resumen de los resultados de las elecciones al Congreso de los Diputados y al Senado convocadas por Real Decreto 977/2015, de 26 de octubre, y celebradas el 20 de diciembre de 2015, conforme a las actas de escrutinio general y de proclamación de electos remitidas por las correspondientes Juntas Electorales Provinciales y por las Juntas Electorales de Ceuta y de Melilla.

5 Comunicado de la Casa de su Majestad el Rey tras la ronda de consultas en virtud del art. 99 de la CE. Palacio de La Zarzuela. Madrid, 22 de enero de 2016. «1. Su Majestad el Rey ha concluido en el día de hoy la ronda de consultas que inició el día 18 de enero con los representantes designados por los Grupos políticos con representación parlamentaria, en cumplimiento del art. 99 de la Constitución. 2. En el transcurso de la última consulta, celebrada con Don Mariano Rajoy Brey, Su Majestad el Rey le ha ofrecido ser candidato a la Presidencia del Gobierno Don Mariano Rajoy Brey ha agradecido a Su Majestad el Rey dicho ofrecimiento, que ha declinado. 3. Su Majestad el Rey ha informado al Señor Presidente del Congreso de los Diputados, Don Patxi López Álvarez, de la decisión de Don Mariano Rajoy Brey. 4. Su Majestad el Rey ha convocado en audiencia al Señor Presidente del Congreso de los Diputados el próximo lunes 25 de enero, a las 17:00 horas, con el objeto de que le facilite la preceptiva lista de representantes designados por los Grupos políticos con representación parlamentaria, para llevar a cabo una nueva ronda de consulta que se iniciará a partir del miércoles día 27 de la próxima semana».

6 Disponible en: http://www.lavanguardia.com/politica/elecciones/20160203/30186 4888800/encargo-rey-pedro-sanchez.html 
Así pues, el día 3 de febrero de 2016 la Casa de su Majestad el Rey presentó la propuesta de candidato a la Presidencia del Gobierno de don Pedro Sánchez Pérez-Castejón, tras celebrarse la segunda ronda de consulta con los representantes designados por los grupos políticos con representación parlamentaria, prevista en el art. 99.1 de CE. Una vez en el Pleno del Congreso de los Diputados, el 2 de marzo tuvo lugar la primera votación, en la que no se logró la mayoría absoluta requerida para este primer trámite. Tampoco se obtuvo la mayoría simple necesaria para aprobar la investidura del presidente de Gobierno en la sesión del 4 de marzo, celebrada como es preceptivo cuarenta y ocho horas después de la primera ${ }^{8}$. No obstante, pese al fracaso de las votaciones, al menos se logró salir de la situación de bloqueo, ya que a partir de la celebración de la primera votación pudo comenzar a correr del plazo de dos meses para la disolución de las Cámaras, establecido en el art. 99.5 de la CE: un plazo que acababa el 2 de mayo. Por otra parte, una vez constatado el fracaso de la investidura propuesta, desde la Casa de su Majestad el Rey no se instaron posteriores rondas de consultas con los representantes parlamentarios, ni tampoco hubo ulteriores propuestas de nuevos candidatos antes de la celebración de las segundas elecciones generales.

De este modo, el 3 de mayo el rey, con el refrendo del presidente del Congreso de los Diputados, expedía el Real Decreto de Disolución de las Cortes Generales y de Convocatoria de Elecciones, siendo la primera vez en democracia en que se convocaban elecciones por la vía del art. 99.5 de la CE. Si bien tras la celebración de los comicios el 26 de junio, el Congreso de los Diputados de la XII legislatura siguió sin ofrecer una mayoría clara, lo cierto es que la lista más votada mejoró sus resultados con respecto a las anteriores elecciones, a diferencia de lo ocurrido con las demás.

Así las cosas, una vez celebradas las consultas con los representantes designados por los grupos políticos con representación parlamentaria, prevista en el art. 99.1 de la CE tuvo lugar la propuesta de candidato a la Presidencia del Gobierno de don Mariano Rajoy Brey, líder de la lista más votada. Al no alcanzarse la mayoría absoluta en el Pleno del 31 de agosto, se convocó un nuevo Pleno tras las cuarenta y ocho horas preceptivas para el día 2 de septiembre en segunda votación, sin que tampoco se lograra esta vez la mayoría simple requerida?.

7 Resultados de la votación celebrada el 2 de marzo: 130 a favor (PSOE, Ciudadanos), 1 abstención (Coalición Canaria), 219 en contra (todos los demás).

8 Resultados de la votación del 4 de marzo: 131 a favor (PSOE, Ciudadanos y Coalición Canaria), 219 en contra (todos los demás).

9 El resultado de ambas votaciones fue idéntico: 170 votos a favor y 180 en contra. Previamente, el día 28 de agosto, el PP y Ciudadanos firmaron un pacto de investidura 
Tras un mes de septiembre sin apenas movimientos, a raíz de los resultados electorales de las elecciones celebradas en las comunidades autónomas de País Vasco y Galicia, que en términos generales supusieron un ulterior refuerzo del PP, así como un debilitamiento del $\mathrm{PSOE}^{10}$, se sucedieron una serie de movimientos bastante rocambolescos en el seno del PSOE que lo llevaron a variar su postura inicial y a favorecer una abstención ante la investidura del líder del PP. Constatada esta situación en la celebración de una nueva rueda de consultas, el rey propuso nuevamente a don Mariano Rajoy Brey como candidato a la Presidencia del Gobierno. En esta ocasión tampoco logró obtenerse la mayoría absoluta requerida en el Pleno celebrado el 27 de octubre de 2016, por lo que se convocó un nuevo Pleno tras las cuarenta y ocho horas exigidas, para el día 29 de octubre. En esta segunda votación, el candidato fue investido con 170 votos a favor (PP y Ciudadanos), 111 en contra y 68 abstenciones (todos los diputados socialistas, menos quince).

\section{FUNCIÓN DE CONTROL AL GOBIERNO}

Ciertamente, la gran cuestión de alcance suscitada en esta breve legislatura que ahora analizamos, aún pendiente de pronunciamiento por parte del Tribunal Constitucional (TC), es la del control parlamentario del Gobierno en funciones $^{11}$. Tanto el jefe del Ejecutivo como sus ministros se negaron desde el primer momento a acudir al Congreso para someterse a las comparecencias de control, así como para responder a las preguntas escritas, al igual que continuaron haciendo en la legislatura actual hasta que el señor Rajoy fue investido presidente. Posteriormente, el 6 de mayo de 2016 tuvo lugar la ratificación oficial de dicha negativa, al presentar el Gobierno en funciones un escrito en respuesta al requerimiento formal formulado por el Congreso de los Diputados. Con base en dicho escrito, el 10 de mayo, la Mesa de la Diputación Permanente del Congreso encargó a los servicios jurídicos de la Cámara la redacción de un conflicto entre órganos constitucionales del art. 73 de la Ley Orgánica del Tribunal Constitucional (LOTC), tal como en su día acordó el Pleno del Congreso con la única oposición del PP, que el TC admitió a trámite el 13 de junio.

que permitió al líder del PP presentarse a la votación de investidura con el apoyo de 170 diputados.

$10 \mathrm{Y}$, en menor medida, también de Podemos y Ciudadanos. Disponible en: http:// www.lavanguardia.com/politica/20160925/41569572310/elecciones-gallegas-elecciones-vascas-feijoo-mariano-rajoy-pedro-sanchez.html

11 Freixes (2016), García Fernández (2016), Martínez (2016) y Vintró (2016). 
En dicho texto, motivaba su negativa en que un Gobierno en funciones «no puede ser sometido a iniciativas de control en la medida en que no existe una relación de confianza entre el Gobierno y el Congreso», ya que un Gobierno solo responde solidariamente ante el Congreso que le ha otorgado su confianza mediante la investidura. Además, al estar en funciones, se decía que el Gobierno no posee la competencia de fijar la orientación política, con lo que carece de sentido el control parlamentario. Asimismo, a favor de la tesis del Gobierno, se ha defendido que no cabe control parlamentario, porque el control parlamentario es control político y el Gobierno en funciones por definición no lleva a cabo actuaciones políticas. En otras palabras, si el Gobierno está en funciones, tiene limitada su actuación al despacho ordinario del día a día administrativo y, por tanto, esa actuación no sería susceptible de fiscalización por parte del Parlamento ${ }^{12}$. El Ejecutivo, además, se basó en su interpretación del art. 21 de la Ley 50/1997, donde aparecen muy restringidas las atribuciones del Gobierno en funciones, así como en las previas y recientes experiencias de Gobiernos en funciones en el ámbito autonómico, en concreto en Cataluña y en Andalucía ${ }^{13}$.

El problema, por tanto, parece ser de principio; esto es, arranca desde la propia idea de control, o más concretamente, de qué debe entenderse por control político, que es el tipo de control llevado a cabo por el poder legislativo sobre el poder ejecutivo en los sistemas parlamentarios como es el nuestro. Y en este caso, creo, la posición amparada por el Ejecutivo en funciones de don Mariano Rajoy supone, entre otras cosas, confundir la función de control con la exigencia de responsabilidad política. Ciertamente, el Congreso de los Diputados no puede exigir la responsabilidad política al Gobierno, puesto que tampoco puede retirar la confianza a un Gobierno a quien previamente no se la ha

12 «En definitiva, la responsabilidad del Gobierno ante las Cortes es única y exclusivamente política. Y por definición un Gobierno en funciones no puede hacer política. Por tanto, tiene razón el Gobierno cuando afirma que no debe ser controlado por ese Parlamento. Solo la excepcionalidad de una decisión política adoptada por urgencia o interés general justificaría que un Gobierno en funciones haga política y que, entonces, el Parlamento controle esa decisión. No tiene razón el Parlamento al querer controlar decisiones políticas del Gobierno en funciones que no se ajusten a urgencia o interés general. En ese caso se ha de acudir al TC para que anule la decisión que ese Gobierno no puede adoptar» (Martínez, 2016).

13 El secretario de estado de relaciones con las Cortes también alegaba, como precedentes, los «largos períodos» de gobierno en funciones tanto de Artur Mas en Cataluña como de Susana Díaz en Andalucía. Disponible en: http:/www.lavanguardia.com/ politica/20160315/40445721552/patxi-lopez-gobierno-evitar-conflicto-institucional-gravecontrol-congreso.html 
otorgado. Pero una cosa es eso y otra muy distinta concluir que el Gobierno puede estar trescientos dieciséis días sin dar cuenta de su actuación ante el Parlamento, por muy técnica, administrativa o limitada que sea dicha actuación gubernamental ${ }^{14}$. Esta concepción del control encuentra su justificación en la propia configuración democrática y pluralista de los Parlamentos, donde tan importante como la concreta decisión finalmente adoptada resulta el propio debate realizado en sede parlamentaria. Esto es, importa tanto el control del Parlamento, como el control en el Parlamento, a través del cual las minorías desempeñan un papel esencial. En este sentido, Aragón Reyes recalca que el control viene ligado al entendimiento del Parlamento como una institución (en tanto representación plural de intereses) y no solo como un órgano constitucional ${ }^{15}$. La publicidad del procedimiento parlamentario y su capacidad de integración de intereses plurales se convierten, así, en la clave del control parlamentario.

Por otra parte, el art. 26.2 de la Ley 50/1997 establece que «Todos los actos y omisiones del Gobierno están sometidos al control político de las Cortes Generales", sin hacer excepciones entre ejecutivos en funciones o en pleno ejercicio de sus atribuciones. En ese sentido, podría decirse más bien, que establecer una limitación de las competencias parlamentarias allí donde ni la $\mathrm{CE}$ ni la ley la disponen supone una restricción indebida de las funciones del Parlamento.

Jurídicamente, la decisión final dependerá del TC, que sigue sin resolver el conflicto entre órganos constitucionales que presentó el Congreso contra el Ejecutivo y que fue admitido a trámite el 23 de junio. Según la LOTC, el TC "resolverá dentro del mes siguiente a la expiración del plazo de alegaciones»", es decir, un plazo que se cumplió ya a finales de agosto de 2016. En el caso

14 «Negar todas las restantes formas de relación (y de control) es falsear (una vez más) la esencia de la democracia parlamentaria, romper las reglas del juego democrático, eludir la rendición de cuentas y evitar la transparencia. Este y cualquier Gobierno en funciones debe, tiene, que mantener sus relaciones “ordinarias” con las Cámaras del Parlamento; y estas relaciones se articulan, entre otras formas, asistiendo a la Junta de Portavoces, cooperando en la formación del Orden del Día de las sesiones, respondiendo a las Preguntas de los diputados, por escrito y de forma oral, en pleno y en comisiones; acudiendo a comparecer cuando se le solicite o por iniciativa propia, etc.» (Paniagua Soto, 2016).

15 Por este motivo, distingue entre «competencia de control» que — como tal competencia- solo sería atribuible al órgano Parlamento y, por otro lado, los «derechos de control», cuya titularidad correspondería a los parlamentarios individuales y grupos parlamentarios, esto es, a la minoría parlamentaria (Aragón Reyes, 1998: 39 y ss.).

16 La Abogacía del Estado solicitó la práctica de dos pruebas: reclamación de los detalles de los antecedentes de 1996, cuando el Gobierno estuvo en funciones hasta la 
que nos ocupa, el pronunciamiento del TC «determinará a qué órgano corresponden las atribuciones constitucionales controvertidas", lo cual solo será de utilidad en el futuro, en el caso de que volviera a presentarse una situación parecida, de un prolongado Gobierno en funciones ${ }^{17}$.

En otro orden de cosas, también relativo a la función parlamentaria de control, hay que recordar que el 11 de abril de 2016 el Grupo Parlamentario Mixto (Compromís) registró en el Congreso una proposición no de ley que instaba al Pleno de la Cámara a reprobar al ministro de Industria, Energía y Turismo en funciones, don José Manuel Soria, a raíz del escándalo suscitado por la aparición de su nombre entre los llamados «papeles de Panamá», esto es, en la documentación interna del despacho panameño Mossack Fonseca, uno de los cinco mayores registradores de sociedades offshore del mundo ${ }^{18}$. El objeto de dicha iniciativa, según explicaron los proponentes, era simplemente intentar forzar la presión sobre el afectado para que él mismo decidiese presentar su dimisión. Dicha iniciativa finalmente caducó, entre otras cosas porque el propio ministro afectado presentó su dimisión cuatro días después de la presentación de la iniciativa mencionada.

\section{FUNCIÓN LEGISLATIVA DEL PARLAMENTO CON UN GOBIERNO EN FUNCIONES}

Una de las primeras cuestiones que se suscitaron tras la constitución de las Cámaras tras las elecciones del 20 de diciembre de 2015 fue la de determinar el alcance de la potestad legislativa de las Cámaras en los supuestos de Gobiernos en funciones, un extremo al que llegan a conclusiones distintas los informes

investidura de José María Aznar, así como el intercambio de escritos entre el Gobierno y el Congreso de los Diputados durante la legislatura fallida.

17 «Esta actuación proyectiva y no meramente reactiva tiene, no hay que explicarlo con detalle, un encaje muy difícil en la tarea propia de un verdadero tribunal como lo es nuestro Constitucional, cuya labor es corregir comportamientos no constitucionales y no ofrecer orientaciones sobre el correcto funcionamiento de la maquinaria del sistema democrático» (Solozabal, 2016).

18 La información se encontraba entre los once millones de documentos de los papeles de Panamá, a los que accede el Consorcio Internacional de Periodistas de Investigación (ICIJ) y el Süddeustche Zeitung, de los que en nuestro país dan cuenta el diario digital El Confidencial, en colaboración con la cadena de televisión La Sexta. Disponibleen:http:/www.elconfidencial.com/economia/papeles-panama/2016-04-11/papelespanama-papers-ministro-soria-offshore-hermano_1179326 
emitidos por las respectivas Secretarías Técnicas de las Cámaras. Si tradicionalmente se había venido esperando a la investidura para la constitución de las Comisiones legislativas y, sobre todo, para dar traslado al Gobierno de las proposiciones legislativas, en esta ocasión la falta de certeza sobre dicha investidura condujo a cuestionarse esta costumbre y, en consecuencia, a no demorar la consideración de las iniciativas legislativas de la Cámara.

Básicamente, el debate se origina debido la prohibición de que el Ejecutivo en funciones presente proyectos de ley [art. 21.5.b) de la Ley 50/97]. A partir de aquí caben dos posturas doctrinales que son, además, las que defendieron cada una de las dos Cámaras. Por un lado, está la postura de los Servicios Jurídicos del Congreso de los Diputados y hecha suya después por la Mesa de la misma Cámara, que no encuentra razones de peso que lleven a impedir el ejercicio de la facultad legislativa en este período de ínterin. En palabras del entonces presidente de la Cámara, Patxi López: «el Gobierno está en funciones, pero el Congreso no». El texto admite sin problemas la tramitación de iniciativas que ya hubieran sido presentadas, de modo que el Gobierno, aun estando en funciones, pudiera pronunciarse en el plazo de treinta días. La principal dificultad, sin embargo, estribaría en la cuestión de las comisiones legislativas, que habrían de ponerse en marcha sin perjuicio de una posterior modificación una vez constituido el nuevo Gobierno, para así poderse adaptar a los ministerios efectivamente existentes.

Por otro lado, nos encontramos con la argumentación sostenida desde el Senado, y también defendida por grandes expertos en la materia como P. García-Escudero, M. Aragón Reyes (en este mismo número) o J. J. Solozabal; una postura que viene a plantearse «si tiene sentido, en un parlamentarismo cooperativo como el nuestro, el ejercicio de la función legislativa por un Parlamento sin Gobierno, titular de la dirección de la política interior y exterior, según el art. 97 de la Constitución, cuyo instrumento fundamental son las leyes $»^{19}$. Así pues, el Informe de la Secretaría General del Senado sobre el ejercicio de las funciones de esta Cámara durante el período de Gobierno en funciones advierte de las excepcionales circunstancias concurrentes en estos supuestos, a la par que aconseja una autorestricción de las Cámaras en la tramitación y eventual aprobación de proposiciones de ley ${ }^{20}$. Estas razones son de tipo esencialista, como las que llevan al profesor Solozabal a criticar duramente al Congreso:

9 García-Escudero Márquez (2016: 116).

20 Ante la imposibilidad de acceder directamente al texto elaborado por la Secretaría técnica, he debido acudir a los comentarios sobre el mismo que lleva a cabo García-Escudero Márquez (id.). 
[...] un Congreso empeñado en deshacer la obra legislativa anterior, sabiendo que posiblemente no dispone de plazo temporal para llevar a cabo esa revocación normativa dados los imperativos del procedimiento parlamentario y sobre todo que no existe un gobierno para llevar a efecto la nueva legislación, proponiéndose así una especie de régimen asambleario convencional, claramente ajeno a nuestro modelo de equilibrio de poderes ${ }^{21}$.

En fin, sin pretender enmendar las tesis defendidas por los valedores de la limitación de las facultades de la iniciativa legislativa parlamentaria, lo cierto es que resulta difícil de justificar tan importante restricción de las facultades parlamentarias sin que esta cuente con un respaldo normativo; no siendo suficiente ampararse una mera interpretación indirecta basada en el concepto de parlamentarismo de colaboración. Además - y como la propia Piedad García-Escudero admite - , ante una prolongada situación de interinidad como la que hemos sufrido en el último año, si bien es cierto que no puede garantizarse la aprobación final de las proposiciones legislativas presentadas, no cabe desconocer que esta no es la única (ni siquiera a veces la principal) finalidad de la minoría parlamentaria al presentar sus iniciativas, sino que caben muchos y diversos objetivos políticos: «desde querer hacer visible al propio Parlamento que no se halla en funciones, hasta realizar una labor de oposición al Gobierno cesante y generar debates que puedan erosionarle, en un escenario de posible precampaña electoral $»^{22}$.

Para seguir con la función legislativa desarrollada en este caso en la primera de las legislaturas analizadas, no puede dejar de mencionarse otra de las novedades desde el punto de vista político constitucional: la presentación — con fecha de 13 de enero de 2016 — de una proposición de reforma de los arts. 87.3, 92 y 166 de la CE, por parte de la Junta General del Principado de Asturias, que fue trasladada al actual Congreso. Como se sostenía en la propia exposición de motivos del texto presentado, «[s]i en España la intervención a través de representantes, a pesar de sus deficiencias, está ya consolidada, no se puede decir lo mismo de la participación directa en sentido estricto (referendos) o en sentido más amplio (plebiscitos, iniciativa legislativa popular, iniciativa popular para la reforma de la Constitución) $»^{23}$.

\footnotetext{
Solozabal (2016).

22 García-Escudero (2016: 116).

23 Artículo único. Uno. El apartado 3 del art. 87 de la CE queda redactado como sigue: «3. Una ley orgánica regulará las formas de ejercicio y requisitos de la iniciativa popular para la presentación de proposiciones de ley. En todo caso, se exigirán 500000 firmas acreditadas, y a las proposiciones de iniciativa legislativa popular les será en todo caso de aplicación lo dispuesto en el apartado 6 del art. 134.
} 
Lo más peculiar de esta iniciativa es que trae causa de una iniciativa legislativa autonómica, algo inédito hasta la fecha. Así pues, el 24 de mayo de 2013 el Parlamento asturiano aprobó una propuesta de reforma de los arts. 87.3, 92 y 166 de la CE con el objeto de mejorar la regulación de las iniciativas legislativas populares, las consultas por vía de referéndum y la iniciativa para impulsar cambios constitucionales ${ }^{24}$.

Por otro lado, debe mencionarse que, además de registrarse proposiciones de leyes (orgánicas y ordinarias), también se presentaron dos propuestas de reforma de Estatutos de Autonomía, el de Canarias ${ }^{25}$ y el de

No procederá dicha iniciativa para la aprobación o modificación de la Ley de Presupuestos Generales del Estado, ni en materias tributarias o de carácter internacional, ni en lo relativo a la prerrogativa de gracia.»

Dos. El art. 92 de la CE queda redactado como sigue:

«1. Las decisiones políticas de especial trascendencia podrán ser sometidas a plebiscito de todos los ciudadanos. Esta consulta será convocada por el Rey, a propuesta del Presidente del Gobierno, previamente autorizado por el Congreso de los Diputados, o a iniciativa de quinientos mil electores.

2. Podrá ser sometida a referéndum la derogación de leyes en vigor, cuando así lo soliciten ante la Mesa del Congreso de los Diputados quinientos mil electores. El resultado del referéndum será vinculante cuando haya participado en la votación la mayoría de quienes tengan derecho a hacerlo y haya sido aprobado por mayoría de los votos válidamente emitidos. No procederá esta iniciativa en materias tributarias, presupuestarias o de carácter internacional, ni en lo relativo a la prerrogativa de gracia.

3. El plebiscito y el referéndum se realizarán en la misma fecha que los procesos electorales de ámbito nacional siempre que coincidan con el mismo año.

4. Una ley orgánica regulará las condiciones y el procedimiento del plebiscito y de las distintas modalidades del referéndum previstas en la Constitución.»

Tres. El art. 166 de la CE queda redactado como sigue:

«La iniciativa de reforma constitucional se ejercerá en los términos previstos en el art. 87.»

Disposición final.

La presente reforma del apartado 3 del art. 87, del art. 92 y del art. 166 de la Constitución entra en vigor el día siguiente al de su publicación en el «Boletín Oficial del Estado».

24 Esta iniciativa, fruto del ejercicio del derecho colectivo de petición impulsado por 7700 personas, supone la inauguración de una vía inexplorada en España de intervención de las comunidades autónomas. M. A. Presno Linera, La Voz de Asturias, 7 de septiembre de 2016. Disponible en: http://www.lavozdeasturias.es/noticia/asturias/2016/09/05/asturias-propuestas-reforma-institucional/0003147309012187248 3358.htm?utm_source=twitter\&utm_medium =referral\&utm_campaign=twgen_a

25 En este caso se trata de una reforma completa del Estatuto de Autonomía, véase http:// www.congreso.es/portal/page/portal/Congreso/PopUpCGI?CMD=VERLST\&BA$\mathrm{SE}=\mathrm{pu} 12 \& \mathrm{DOCS}=1-1 \& \mathrm{DOCORDER}=\mathrm{LIFO} \& \mathrm{QUERY}=\% 28 \mathrm{BOCG}-12-\mathrm{B}$ $-10-1 . C O D I . \% 29 \#$ 
Valencia ${ }^{26}$, presentados ambos el 13 de enero de 2016 por sus respectivas asambleas autonómicas y que han sido trasladados al actual Congreso.

Por último, y a modo de simple enumeración, debe destacarse que las disposiciones legislativas finalmente aprobadas en este período de Gobierno en funciones fueron dos leyes orgánicas: la Ley de Reforma de la Ley Orgánica 2/2012, de 27 de abril, de Estabilidad Presupuestaria y Sostenibilidad Financiera; y la Ley de Modificación de la Ley Orgánica 5/1985, de 19 de junio, del Régimen Electoral General, para el supuesto de convocatoria automática de elecciones en virtud de lo dispuesto en el apartado 5 del art. 99 de la CE.

En cuanto a la actividad legislativa del Gobierno, solo se aprobó el Real Decreto-Ley 1/2016, de 15 de abril, por el que se prorroga el Programa de Activación para el Empleo y la Corrección de Errores en el Real Decreto Legislativo 8/2015, de 30 de octubre, por el que se aprueba el texto refundido de la Ley General de la Seguridad Social, que en puridad no es un decreto legislativo, ciertamente.

\section{EL VETO PRESUPUESTARIO DEL GOBIERNO}

Sin duda, otra de las grandes cuestiones polémicas generadas en estos convulsos días de interregno fue (y sigue siendo) la del frecuente uso (y quizás abuso) que el Ejecutivo en funciones hizo de su prerrogativa de veto por motivos presupuestarios a las proposiciones de $\operatorname{ley}^{27}$. En efecto, durante el mes de

26 Su contenido material hace referencia a la financiación autonómica: «Disposición adicional primera. 1. La inversión del Estado en la Comunitat Valenciana, excluido el Fondo de Compensación Interterritorial, será equivalente al peso de la población de la Comunitat Valenciana sobre el conjunto del Estado por un periodo de siete años. 2. Con esta finalidad se constituirá una comisión integrada por la administración estatal y autonómica».

27 El art. 134.6 de CE exige el consentimiento del Gobierno con carácter general para la tramitación de todas las enmiendas o proposiciones de ley que supongan «aumento de los créditos o disminución de los ingresos presupuestarios». En el Congreso de los Diputados, en cambio, se establece un procedimiento diferenciado según se trate de proposiciones o de enmiendas. Para la primera categoría el art. 126.2 del Reglamento del Congreso prevé que sea la Mesa de la Cámara el órgano encargado de enviar al Ejecutivo todas las proposiciones presentadas. Por el contrario, cuando se trata de enmiendas, el art. 111.2 del citado Reglamento atribuye auténticas funciones calificadoras a la Ponencia de la Comisión encargada de la redacción del informe, ya que será dicha Ponencia, a través del presidente del Congreso, la encargada de remitir 
octubre el Ejecutivo vetó la tramitación de diez proposiciones de ley presentadas por los grupos de la oposición y por varias asambleas legislativas de las comunidades autónomas, haciendo uso de su facultad de rechazar aquellas iniciativas que, a su juicio, afecten a los ingresos o gastos presupuestarios. En concreto, el Gobierno en funciones no otorgó su autorización a la tramitación de cinco proposiciones de ley del grupo parlamentario socialista (paralización de la Ley Orgánica de Mejora de la Calidad Educativa [LOMCE]), trabajadores subcontratados, supresión de tasas judiciales, pobreza energética y universalización de la asistencia sanitaria), una de Ciudadanos (sobre autoconsumo eléctrico) y cuatro de asambleas legislativas autonómicas (una de la Asamblea Regional de Murcia sobre autoconsumo energético, otra del Parlamento vasco para compensar a víctimas del amianto, otra del Parlamento de Galicia para asumir la titularidad de la autopista de peaje AP-9, y otra del Parlamento balear sobre emprendedores). El Gobierno motivaba su decisión en que, de aprobarse dichas proposiciones de ley, implicarían una desviación presupuestaria de más de cinco mil millones de euros, con el consecuente incumplimiento del plan de estabilidad comprometido con la Unión Europea (UE).

En la práctica parlamentaria española, sin embargo, lo normal ha sido que los sucesivos ejecutivos hayan evitado la utilización de esta facultad, ya que se ha preferido actuar desde el propio Parlamento, dejando que fuese la mayoría parlamentaria que lo apoyaba quien, en su caso, rechazase las proposiciones de ley provenientes de la oposición. Desde el punto de vista institucional, se ha interpretado como un intento de favorecer la libre actuación de las Cámaras y de fomento del debate parlamentario; mientras que, desde una perspectiva más escéptica, podría decirse que los sucesivos ejecutivos han evitado contaminar su imagen pública y ofrecer un perfil más amable y dialogante. La única excepción a este comportamiento la encontramos en la segunda legislatura del presidente Rodríguez Zapatero, en la que casi un centenar de proposiciones de ley formuladas por diferentes grupos parlamentarios sufrieron el veto del Gobierno, lo que impidió su toma en consideración por el pleno del Congreso de los Diputados ${ }^{28}$.

aquellas enmiendas que, «a su juicio», puedan conllevar un aumento de créditos o una disminución de los ingresos.

28 De las 115 proposiciones de ley vetadas hasta ahora, 93 datan de la segunda legislatura de José Luis Rodríguez Zapatero, a raíz de la adopción de medidas de ajuste para el cumplimiento de los compromisos presupuestarios con la UE. Disponible en: http://www.europapress.es/nacional/noticia-mesa-congreso-debate-manana-vetos-gobierno-amenaza-conflicto-20161128174811.html 
Sin embargo, lo peculiar de esta situación no radicó tanto en el veto del Gobierno en sí, dado que, aunque poco frecuente tampoco resultaba enteramente inédito, sino más bien en la reacción del Congreso de los Diputados frente a dicha decisión del Ejecutivo. En efecto, la Mesa del Congreso tras examinar dichos vetos del Gobierno, consideró que dos de ellos resultaban injustificados (concretamente, la proposición de ley para la mejora de las condiciones de los trabajadores subcontratados, que proponía una reforma en este punto del Estatuto de los Trabajadores, y la proposición de reforma de la LOMCE), mientras que para las restantes proposiciones de ley dejaba su tramitación temporalmente en suspenso, en espera de la solicitud de un informe a los servicios jurídicos de la Cámara.

A este respecto, la Mesa solicitó un informe a sus letrados, donde se defendía «la posibilidad de que en aquellos casos en que se ha presentado por algún grupo parlamentario un escrito de oposición al criterio el Gobierno [...] la Mesa acuerde trasladar el mismo al Gobierno, requiriéndole motivación adicional o complementaria». Además, en dicho informe se recordaba la obligación de la Mesa de garantizar los derechos fundamentales de los diputados frente a eventuales abusos del Gobierno al vetar sus iniciativas ${ }^{29}$. No está de más recordar con relación al requisito de la motivación de la respuesta del Gobierno que, si bien el Reglamento del Congreso solo lo exige respecto de las enmiendas, debe entenderse aplicable, a fortiori, respecto de las proposiciones de ley.

Sin embargo, la iniciativa que ha acabado convirtiéndose en el principal objeto de polémica era una proposición de ley presentada por PSOE, Unidos Podemos, ERC, PNV y Pdecat, que establecía una subida de todas las pensiones del 1,2\% a partir del 1 de enero de 2017 con el objeto de garantizar el poder adquisitivo de los pensionistas ${ }^{30}$. Frente al veto del Gobierno, el PSOE sostenía que dicha objeción «no resulta razonada, objetiva y suficiente», ya que los cálculos venían referidos a 2017. Ello afectaría, pues, a unos presupuestos aún pendientes de aprobación, mientras que el Ejecutivo solo puede vetar iniciativas que afecten a los presupuestos vigentes; motivo

29 Véase http://www.elperiodico.com/es/noticias/politica/mesa-congreso-decide-informeletrados-veto-gobierno-recurso-lomce-iniciativas-oposicion-5658871

30 Este texto pretende derogar el mecanismo de revalorización de pensiones aprobado en 2013, con el que desde entonces se han incrementado un $0,25 \%$, mientras que el art. 2 de la proposición de ley comentada prevé que, en caso de que la inflación acumulada en 2017 supere el 1,2\%, «las pensiones se revalorizarán de forma adicional en el porcentaje correspondiente a la diferencia entre el 1,2\% y el crecimiento real del IPC», evitando así afectar el poder adquisitivo de los pensionistas. 
por el cual solicitó a la Mesa la continuación de la tramitación de la citada proposición de ley.

Por su parte, el Ejecutivo manifestó su intención de recurrir esta decisión ante el TC, ya que, por ejemplo, respecto del supuesto de la propuesta de ley de suspensión de la LOMCE, el Gobierno alegaba que, de paralizarse su calendario de aplicación, España sufriría una pérdida de ingresos de unos 615 millones de euros provenientes de Fondos Europeos. En esta línea, el Ejecutivo presentó un requerimiento formal de reconsideración ante la Mesa del Congreso para que la Cámara rectificara su negativa a atender los vetos, lo que constituye el paso previo a la interposición en el TC de un conflicto de atribuciones entre el Gobierno y el Congreso de los Diputados ${ }^{31}$. En consecuencia, esta cuestión acabó en nuevos conflictos de atribuciones con el Congreso de los Diputados ${ }^{32}$, que se unirá así al anteriormente expuesto relativo a la negativa del Gobierno en funciones a someterse al control parlamentario ${ }^{33}$. En este caso, nos encontramos ante una situación que ha excedido el período objeto de nuestro análisis y que se proyecta al resto de la legislatura, caracterizada por un Gobierno en minoría, que augura una constante litigiosidad, y un intercambio de vetos ${ }^{34}$, ya que el Gobierno puede paralizar la tramitación de

31 Se podía leer esos días en la prensa que el Ejecutivo había venido manifestando su convicción en el respaldo del TC a sus vetos, lo que conllevaría no solo la nulidad de las leyes eventualmente aprobadas sin respetarlos, sino también la exigencia de responsabilidades al Estado legislador por la pérdida de ingresos producida. Por otro lado, tampoco se esconde la más o menos velada amenaza tras la actitud del Gobierno, que podría proceder a la disolución de las Cámaras a partir del 3 de mayo de 2017, si considera que las iniciativas parlamentarias suponen un exceso de gastos que imposibilita el desarrollo del programa de Gobierno. Disponible en: http://www.europapress.es/ nacional/noticia-mesa-congreso-debate-manana-vetos-gobierno-amenaza-conflicto-20161128174811.html

32 Acuerdos adoptados por el Consejo de Ministros de 13 de enero de 2017.

33 «[...] aunque en un sistema parlamentario los eventuales conflictos entre las Cortes y el Gobierno deben resolverse normalmente a través de los instrumentos de control que garantizan la supremacía de aquéllas, es claro que estos conflictos sólo pueden producirse legítimamente dentro del marco constitucional y que, cuando se suscitan fuera de él, la solución no debe buscarse a través de las relaciones de supra y subordinación, sino a través de la decisión del órgano garante de la Constitución»(Rubio Llorente y Aragón Reyes, 1984: 885).

34 El Gobierno, posteriormente, el 14 de noviembre de 2016, ya en pleno ejercicio de sus funciones volvió a vetar diez proposiciones de ley de los grupos PSOE, Unidos Podemos y Ciudadanos. El Gobierno motivaba dicha oposición a la tramitación de las diez iniciativas en la presunta desviación presupuestaria de más de cinco mil millones 
iniciativas de la oposición, mientras que esta puede rechazar o enmendar las presentadas por el Ejecutivo.

El problema reside aquí —como señalaba recientemente Martínez Lago- en que el privilegio constitucional que tiene el Gobierno de oponerse a iniciativas que causen modificaciones en los Presupuestos «es inaplicable hasta tanto no se hayan aprobado por el Parlamento y comiencen a ejecutarse. Los efectos deben constatarse sobre unos Presupuestos en vigor. Incluso sobre unos Presupuestos prorrogados, pero solo a partir de su prórroga $»^{35}$.

En este sentido, es posible distinguir en el veto presupuestario dos elementos esenciales. En primer lugar, el requisito para que pueda tener lugar es que, efectivamente, la enmienda o la proposición de ley, de aprobarse finalmente, suponga el aumento de los créditos o la disminución de los ingresos presupuestarios. Este primer requisito actuaría, pues, como un supuesto de hecho habilitante, sin el cual no existiría la facultad de veto del Gobierno. El segundo de los elementos, pues, sería el de la propia declaración de voluntad del Gobierno que mostraría su disconformidad con la tramitación de la enmienda o de la proposición de ley, con el que se evitaría su aprobación, «precisamente por no considerar conveniente que se produzca ese efecto o repercusión presupuestarios ${ }^{36}$.

En definitiva, la capacidad de calificación de la Mesa podría entenderse limitada precisamente a controlar precisamente si concurre la circunstancia que habilita al Ejecutivo a ejercer su disconformidad a la tramitación de una proposición de $\mathrm{ley}^{37}$. De hecho, siendo rigurosos, el conflicto de intereses en

de euros, que arriesgarían el cumplimiento del plan de estabilidad comprometido con la UE. Un resumen de las motivaciones ofrecidas por el Ejecutivo en: https:// www.cuartopoder.es/laespumadeldia/2016/11/30/rajoy-veta-16-leyes-socialesde-la-oposicion-y-las-autonomias-en-42-dias/21451

Martínez Lago, M. Á. (2011 y 2016).

Marrero García-Rojo, Á. (2007).

37 El TC en dos pronunciamientos sucesivos parece reconocer esta facultad implícita al Ejecutivo, como consecuencia directamente derivable del «parlamentarismo racionalizado» como forma de gobierno. Por otra parte, dichos pronunciamientos del TC resultan contradictorios con respecto a la existencia e intensidad de la capacidad de control de la Asamblea respecto del veto opuesto por el Ejecutivo: por un lado, la STC 223/2006 había defendido el carácter "políticamente libre» del Gobierno en el ejercicio de dicha facultad, mientras que en la posterior STC 242/2006 se sostiene que la Mesa del parlamento (en ese caso el vasco) sí tiene margen de decisión y control frente al veto del Gobierno. Un tema este que, sin duda, deberá precisar el TC, pues sin duda plantea no pocos interrogantes. Para mayores desarrollos de esta cuestión me remito a lo ya expuesto en Giménez Sánchez, I.M. (2008 y 2005). 
realidad no se plantearía directamente entre Parlamento y Gobierno, sino entre el Gobierno, por un lado, y los diputados autores de las enmiendas o proposiciones de ley, que no necesariamente tienen que coincidir con mayorías parlamentarias. Así pues, como muy bien destaca Marrero, «[d] esde esta estricta perspectiva, el Parlamento es un tercero a dicho conflicto, del que no cabe presumir (ni jurídicamente ni en la práctica, desde luego) que vaya a apreciar ese carácter manifiestamente infundado en la actuación gubernamental $\aleph^{38}$. Es más, en la situación de los juegos de mayorías parlamentarias como en las dos legislaturas analizadas no resulta previsible la existencia de mayorías ni de alianzas automáticas en el Parlamento que lleven a hacernos sospechar de un prejuicio de la Mesa en contra de las decisiones del Gobierno.

\section{OTRAS INICIATIVAS}

En este apartado cabría destacar la creación de una Subcomisión para el Estudio de las Mejores Prácticas, el Seguimiento y Propuestas de Medidas para el Empleo entre el colectivo de menores de treinta años en el Congreso de los Diputados.

También se solicitó por un lado la creación de diversas comisiones de investigación (art. 52 del Reglamento del Congreso): sobre las presuntas irregularidades en la empresa pública ACUAMED y sobre los denominados «Papeles de Panamá», así como su relación con la amnistía fiscal; y por otro de las más variadas Subcomisiones y Ponencias ${ }^{39}$.

Marrero García-Rojo (2007: 328).

39 Solo en la llamada legislatura fallida, se solicitó la creación de una ponencia para la reforma del Reglamento del Congreso de los Diputados; de una Subcomisión, en el seno de la Comisión de Hacienda y Administraciones Públicas, sobre la armonización y coordinación fiscal europea e internacional y lucha contra el fraude fiscal y los paraísos fiscales; de una Subcomisión, en el seno de la Comisión de Economía y Competitividad, para el análisis de la economía colaborativa; de una Subcomisión, en el seno de la Comisión de Defensa, para el estudio del régimen profesional de los militares de tropa y marinería de las Fuerzas Armadas; una Subcomisión, en el seno de la Comisión de Agricultura, Alimentación y Medio Ambiente, para el estudio de las dificultades que afectan al sector lácteo y posibles soluciones; una Subcomisión, en el seno de la Comisión de Empleo y Seguridad Social, para el apoyo, estímulo y reformas necesarias del régimen jurídico aplicable a la Economía Social; una Subcomisión, en el seno de la Comisión de Cooperación Internacional para el Desarrollo, sobre la aplicación de la Agenda 2030 desde un enfoque de coherencia de políticas para el desarrollo en España; una Subcomisión, en el seno de la Comisión de Empleo 
Por lo que respecta a las proposiciones no de ley presentadas, sobre todo referidas a la breve legislatura, la inmensa mayoría (más de veinte) de las proposiciones registradas, especialmente las del grupo socialista, tienen por objeto cuestiones muy concretas relativas a Fomento o Industria (por ejemplo, sobre el mantenimiento del taller de reparaciones de Venta de Baños por Renfe Operadora o sobre el tramo de AVE denominado Variante de Pajares) y solo unas pocas vienen referidas a aspectos de política general (sobre medidas para garantizar el derecho fundamental de libertad sindical y el derecho fundamental de huelga, sobre medidas para impulsar la igualdad de género en el sistema científico español, sobre la igualdad salarial entre mujeres y hombres, relativa a impulsar el Plan Concertado de Prestaciones Básicas de Servicios Sociales y devolver a las entidades locales las competencias en materia de prestación de los servicios sociales, relativa a garantizar el desarrollo y la financiación del Sistema de Autonomía y Atención a la Dependencia, sobre conciliación y corresponsabilidad).

\section{Bibliografía}

Aragón Reyes, M. (1998). Sistema parlamentario, sistema presidencialista y dinámica entre los poderes del Estado. Análisis comparado. En Pau i Vall, F. (coord.). Parlamento y control del Gobierno (29-46). Madrid: Asociación Española de Letrados de Parlamentos.

Azpitarte Sánchez, M. (2016). El agotamiento del bipartidismo. Crónica política y legislativa del año 2015. Revista Española de Derecho Constitucional, 106, 205-232. Disponible en: https://doi.org/10.18042/cepc/redc.106.05

Freixes, T. (2016). El control parlamentario del Gobierno en funciones. El Español, 18-3-2016. Disponible en: http://www.elespanol.com/opinion/20160317/110358965_12.html

y Seguridad Social, para el análisis de las reformas necesarias del Régimen Especial de los Trabajadores Autónomos, para la mejora del régimen de protección social y para garantizar su competitividad; una Subcomisión, en el seno de la Comisión de Industria, Energía y Turismo, para el análisis y estudio de medidas que impulsen la modernización de la industria española a través del Internet de las cosas y el desarrollo de la Industria 4.0.; una Subcomisión, en el seno de la Comisión de Industria, Energía y Turismo, sobre el Proyecto Castor; una Subcomisión, en el seno de la Comisión de Sanidad y Servicios Sociales, para la propuesta de políticas integrales en relación con los trastornos de conductas alimentarias; así como una Subcomisión, en el seno de la Comisión de Hacienda y Administraciones Públicas, para la medición de la economía sumergida, la lucha contra el fraude fiscal y la mejora de la eficiencia tributaria. 
García-Escudero Márquez, P. (2016). Gobierno en funciones y función legislativa. Cuadernos Manuel Giménez Abad, 11, 101-116.

García Fernández, J. (2016). El Gobierno en funciones ante el control del Congreso. Ahora, 29, 15-04-2016. Disponible en: https://www.ahorasemanal.es/el-gobierno-en-funcionesante-el-control-del-congreso

Giménez Sánchez, I. M. (2005). La intervención del Gobierno en el ejercicio de la función presupuestaria. En Aragón Reyes, M. y Gómez Montoro, A. J. (coords.). El Gobierno. Problemas constitucionales (pp. 287-335). Madrid: CEPC.

- (2008). Las competencias presupuestarias del Parlamento. Madrid: CEPC.

Gómez Montoro, A. J. (1992). El conflicto entre órganos constitucionales. Madrid: CEC.

Marrero García-Rojo, Á. (2007). El control del ejercicio por el Gobierno de la facultad de veto presupuestario (comentario a la STC 223/2006, con consideración de la STC 242/2006). Revista Española de Derecho Constitucional, 80, 309-359.

Martínez Martínez, R. (2016). Controlar a un Gobierno en funciones. El Periódico, 25-3-2016. Disponible en: http://www.elperiodico.com/es/noticias/opinion/controlar-gobiernofunciones-5001212

Martínez Lago, M. Á (2011). Notas sobre el veto presupuestario en las relaciones Gobierno-Parlamento. El Cronista del Estado Social y Democrático de Derecho, 21, 52-63.

- (2016). El abuso del veto presupuestario del Gobierno. Infolibre, 04-12-2016. Disponible en: http://www.infolibre.es/noticias/opinion/2016/12/05/el_abuso_del_veto_ presupuestario_del_gobierno_58389_1023.html

Paniagua Soto, J. L. (2016). El control del Gobierno en funciones. El País, 24-03-2016. Disponible en: http://elpais.com/elpais/2016/03/23/opinion/1458761062_349708.html.

Rubio Llorente, F. y Aragón Reyes, M. (1984). La jurisdicción constitucional. En A. Predieri, A. y E. García de Enterría (coords.). La Constitución española de 1978. Madrid: Civitas.

Solozabal Echavarria, J. J. (2016). La nefasta interinidad prolongada del Gobierno. El Imparcial, 12-04-2016. Disponible en: http://www.elimparcial.es/noticia/163719/opinion

Vintró, J. (2016). Gobierno en funciones y control parlamentario. Agenda Pública, 13-03-2016. Disponible en: http://agendapublica.es/gobierno-en-funciones-y-control-parlamentario 